\title{
Zur Verständigung.
}

(Aus einem Briefe an Dr. Bley von Dr. Duflos.)

Ich bedaure sehr, unabsichtlich Herrn Dr. Mohr Veranlassung gegeben zu haben, meiner in der eigenthümlichen freundlichen Weise zu gedenken, wie im Junihefte dies. Archivs S. 293 geschehen. Herr Dr. Mohr thut mir sehr unrecht, wenn er die Vermuthung ausspricht, dass sein Commentar mir unbekannt sei. Ich kenne das Werk sehr wohl, schätze es als eine sehr gediegene Arbeit hoch und suche nach Kräften in meinem Wirkungskreise zu dessen Verbreitung beizutragen, obwobl mich, wie gewiss viele Andere, die häufig verletzende Schreibweise des Verfassers nicht anspricht. Die von mir im Archiv (Bd.53. S. 81) gegebenen Notizen sind nur ein kleiner Auszug dessen. was ich im Semester 18 $\frac{16}{\frac{1}{7}}$, lange vor dem Erscheinen der ersten Lieferung des Mohr'schen Commentars, in einem Cyclus von Vorlesungen*) uber die zu jener Zeit noch nicht ausgegebene 6te Ausgabe der Preuss. Pharmakopöe vorgetragen habe, und was z. B. die in den mitgetheilten Notizen bei Acetum concentratum und Acidum hydrocyanatum angegebenen Verhältnisse an Schwefelsäure betriff, so stimmen dieselben ja im Wesentlichen mit

") In der Meinung, dass beim Beginnen des genannten Semesters die neue Pharmakopöe vollendet sein würde, hatle ich in dem Lectionscatalng unter andern Vorlesungen auch Dissertationes de Pharm. Boruss. novissima, cujus editio instat, angekündigt. Als aber der Termin für Beginn der Vorlesungen (15. October 1846) heranrückte, und die Pharmakopöe noch nicht erschien, so wandte ich mich an das betreffende Königl. Ministerium mit dem Gesuche, mir die Benutzung der bis dabin fertigen Bogen zu dem genannten Zwecke zu gestatten, was mir denn auch gewährt wurde. Anfangs war es meine Absicht, die gehaltenen Vorträge für sich als Broschüre erscheinen zu lassen; durch vielfache anderweitige Geschäfte jedoch von der in solchem Falle nothwendigen Ueberarbeitung abgehalten, begnügle ich mich damit, aus diesen Vorträgen einige Notizen ausziehen zu lassen und Ihnen für das Arcbir einzusenden. 
denen überein, welche sich in meinem bereits 1813 erschienenen Apothekerbuch angegeben finden. Dass ich daher nachträglich des Herrn Mohr nicht erwähnt habe, kann mir wohl Seitens desselben nicht zum Vorwurf gemacht werden; mit grösserem Recht könnte es mich befremden, dass Herr Mohr, wo er der quantitativen Bestimmung der Blausäure Erwähnung thut, nichts davon erwähnt, dass die von ihm beschriebene Bestimmungsweise zuerst von mir in Vorschlag gebracht und angewendet worden ist*).

Am a. O. S. 82 und 83 hat sich allerdings, wie Herr Dr. Mohr bemerkt, ein Irrthum eingeschlichen, und es ist das Aequivalent des Kalis fir das des Natrons in Rechnung gebracht worden ${ }^{*}$ ); es muss demnach an der ersten stelle heissen:

$\left\{\begin{aligned} \mathrm{NaO} & =31 \\ \mathrm{C}^{4} \mathrm{H}^{3} \mathrm{O}^{3} & =51 \\ 6 \mathrm{HO} & =54\end{aligned}\right\} 136$ erfordern zur Zerselzung $\mathrm{HO}, \mathrm{SO}^{3}=$ 49, folglich $136: 49=36: 13$, also in Berücksichtigung u. s. w. höchstens 16 von dicser letzteren; ebenso S. 83: Auf $\mathrm{NaO}, \overline{\mathrm{A}} \mathrm{c}=82$ würden hinreichen $\mathrm{KO}, \mathrm{HO}, 2 \mathrm{SO}^{3}=136,12$, also auf 12 des ersteren 20 des letzteren, welche man zweckmässig auf $22-23$ erhöhen kann. S. 84 muss es heissen: 4 Thlr. statt 1 Thlr.

*) Dass das salpetersaure Silberoxyd die Blausäure aus den ätherisch-öligen blausäurchaltigen destillirten Wässern nicht vollsıändig ausfällt, ist von Sch $r$ ader, von dem überhaupt dic Anwendung des Silbersalpeters zur Bestimmung der Blausäure herrührt, bereits bemerkt worden (Berl. Jahrb. Jahrg. XXVII. S. 60), daher von mir anstait des leztern bereits 1829 (Kastn. Arch. XIV. Brandes' Arch. XXIX.) die ammoniakalische Silberlösung vorgeschlagen wurde. Nach einer Stelle in Mo h r's Commentar (S. 212) kõnnte es scheinen, als wenn dies gleichgültig wäre.

*) Es rührt dies daher, dass in dem mannigfaltig corrigirten ausführlichen Nanuscript neben der Rechnung für das Natronsalz auch die für das Kalisalz behufs der Vergleichung mit der Vorschrift der frühern Pharmakopöe eingeschaltet war und späterhin als die für. das Archiv bestimmten Notizen ausgezogen werden sollten, irrthümlich die erstere stalt der letztern ausgestrichen wurde. 